\title{
Estimating the hidden economy in Bulgaria*
}

\begin{abstract}
Summary
Estimating the size of the hidden economy in transitional countries in eastern Europe is a very important task. This paper reports the results of an independent study of the hidden economy in Bulgaria. The study was conducted in 2007-2008 and was based on a survey of 345 companies in Bulgaria. The main findings of the study are as follows: 1. The size of the hidden economy in Bulgaria was found to be considerably larger than the official estimates. It was estimated by business sector respondents as comprising 42 per cent of GDP in 2007. The size of the hidden economy decreased slightly between 2002 and 2007. 2. The economic sector with the largest hidden economy was construction, followed closely by the retail and wholesale trades. 3. The two most important indicators of the hidden economy were hidden labour and hidden economic activity by firms. 4. The most important reasons for the existence of a hidden economy were: corruption; the lack of penalties for unlawful economic activity; and the ineffective judicial system.
\end{abstract}

\section{Introduction}

The statistical evaluation of the size and distribution of the hidden economy has traditionally been considered a challenge for economic statistics. For Bulgaria, this is an even more challenging task because of the unreliability of the statistical information and the importance of the issue with regard to Bulgarian integration in Europe.

There are a number of problems related to the statistical evaluation and empirical investigation of the hidden economy. In this paper, the emphasis is on the statistical approach, which could enable us, first, to evaluate the size of the hidden economy, second, to compare the results with other countries and, third, to investigate the dynamics of the hidden economy.

The hidden economy is sometimes defined too narrowly or too broadly, which makes it difficult to develop models. Many different adjectives are used, sometimes interchangeably, such as: 'grey', 'unreported', 'shadow', 'informal', 'unobserved', 'underground', 'black', 'illegal', and so on (see Schneider and Klinglmair, 2004; Schneider and Enstle, 2002).

Part of the problem is that the hidden economy can be analysed from different perspectives, including legal, fiscal, labour, statistical and so on. For example, it is tempting to define the phenomenon as the 'illegal' economy, that is, the result of illegal economic activities. However, there are many legal activities which, for various rea-

* The author would like to acknowledge the support of the Research Division of the University of National and World Economy (UNWE), Sofia, Bulgaria. The author was the principal investigator of the project titled 'Hidden economy in Bulgaria: Contemporary evaluation in the period of European integration'. 
sons, remain unaccounted for. The definition of the hidden economy has to be precise enough to allow quantification at a later stage.

The OECD defines the 'non-observed' economy as activities unaccounted for in the official data, used for the national accounts, because they are 'underground', 'illegal', 'informal' or consist of the production of households for own use, or are the result of discrepancies in the data collection system (OECD, 2002a).

There are three main elements of the 'non-observed' economy, according to the OECD manual (OECD, 2002a):

1. 'underground' - legally registered economic activities, but partially unreported, usually in order to avoid taxes. Usually, such types of activity are labelled the 'grey' economy.

2. 'illegal' - includes activities explicitly or implicitly forbidden by law, for example, production and distribution of illegal drugs, prostitution, illegal gambling, pirate copies of movies and musical products, printed materials and software. These activities are usually referred to as the 'shadow' economy.

3. 'informal' - economic activities of households. They are legal but unregistered and unaccounted for. They are most often referred to as the 'informal' economy.

Figure 1 - Conceptual model of the hidden economy

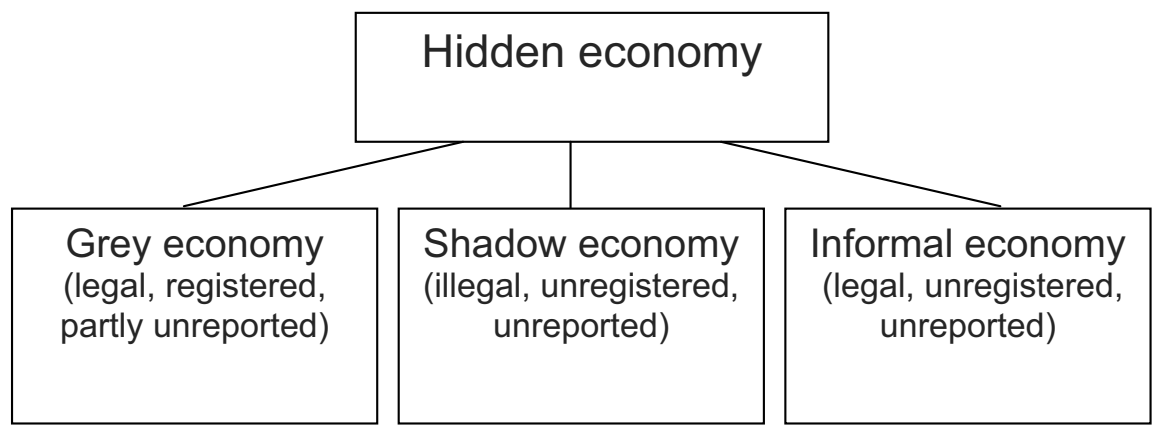

These three elements - grey, shadow and informal - largely account for the hidden economy. In this study, the 'informal' economy is not evaluated. A similar approach was taken by the Bulgarian Centre for the Study of Democracy (CSD, 2003 and 2004). The reason is that the respondents were from the business community and were not in a position to evaluate the 'informal' economy. For the 'informal' economy we can rely on the estimates of the Bulgarian NSI. The discrepancies with regard to data collection are not included in this definition because it is not directly related to the main interpretation of the hidden economy.

EUROSTAT (OECD, 2002b) has developed a classification of corrections for the hidden economy for national accounts, the so-called 'Model T1-T8'. Elements T1 to T8 are as follows: 
T1 - no answer on the survey

T2 - no actual registration in the statistical registry, for example, entities that do not exist anymore; newly-registered but not included in the official registry; problems due to acquisitions and mergers, splits and other transformations; entities with incorrect information about their size, sector, address registration, and so on

T3 - lack of registration of existing entities, for example, very small companies not required to register for statistical purposes or due to inconsistencies in the statistical registry

T4 - under-reported and untruthful entries, for example, entities that hide part of their revenue, or report inflated and distorted costs

T5 - unregistered activities; for example, the company is registered in general but its activity is under-reported because some of its divisions or subcontractors remain unregistered

T6 and T8 - lack of information on household production for self-consumption, including food production, clothing, cleaning, residential building activities and so on

T7 - lack of information on illegal activities, including illicit drugs production and distribution, prostitution, unregistered gambling, smuggling, and so on.

The methods for evaluating and estimating the hidden economy can be divided into two groups: direct and indirect (see Stoikov and Dimitrova, 1999a and 1999b; Belev, 2002 and 2003). Direct methods use sample survey methodology to estimate the size of the hidden economy, while indirect methods use indicators and econometric models for the evaluation of variables which reflect its share (for example, Schneider and Klinglmair, 2004; Dudeva, 2001; Iliev, 2004).

\section{Some existing estimates of the hidden economy in Bulgaria}

- NSI includes an estimate of the hidden economy based on the system of national accounts (SNA) (based on OECD, 2002a and 2002b). The general estimate is 12.5 per cent of 2007 GDP, which includes 9.2 per cent for the grey economy, 2 per cent for the informal economy and 1.3 per cent for the shadow economy (author's personal correspondence with NSI SNA Department chair)

- Schneider (2006) estimates the size of the hidden economy to be 38 per cent of GDP for 2002/2003, using the DYMIMIC model

- Feige and Urban (2007) evaluate the average size of the hidden economy at 19 per cent of GDP for 1990-2001 by a physical input method, applying a model with electricity consumption as one of the main indicators (MEC: method of electricity consumption)

- in the second half of the 1990s, research fellows at the Institute of Economics at the Bulgarian Academy of Sciences conducted a survey which yielded an estimate of about 40 per cent for the share of the hidden economy in GDP for 1998 (Stoikov and Dimitrova, 1999b)

- in 2000, a research team from the Institute for the Market Economy, the Agency for Economic Analysis and Forecasting, Harvard University and Cornell University carried out an empirical study of the hidden economy in Bulgaria. Using the MEC 
physical input method, an estimate of about 25 per cent was obtained for 1999 (Kyle et. al, 2001).

The author has previously addressed a number of methodological issues related to research on the hidden economy (Goev, 2007; Goev and Boshnakov, 2003 and 2008).

Some estimates of the hidden economy in other east European countries

- Schneider (2006) estimates the size of the hidden economy for 145 countries, using the DYMIMIC model, including Romania (37 per cent), Greece (28 per cent), Macedonia (36 per cent), Russia (49 per cent), Hungary (26 per cent) and Turkey (34 per cent). The lowest estimate is for the USA ( 8 per cent) and the highest for Georgia (68 per cent)

- Feige and Urban (2007) evaluate the size of the hidden economy for Romania at 9 per cent, Macedonia at 31 per cent, Russia at 28 per cent, Hungary at 22 per cent and the Czech Republic at 14 per cent. These estimates are of the average size of the hidden economy for 1990-2001 using a model with electricity consumption as one of the main indicators (MEC: method of electricity consumption).

The official estimates indicate that the size of the hidden economy in Bulgaria is not very large in comparison to other East European countries. Our study will show that the official estimates are too low. Our estimate is much higher than the official one but it does not much differ from other independent estimates (for example, Schneider, 2006).

There are no reliable estimates of the hidden economy in Bulgaria after 2005. This is one reason why our study is particularly valuable and timely. The second reason is that we put the estimates in the hands of business people who are very knowledgeable about current economic processes in Bulgaria and who have no obvious interest in distorting their estimates. They gave separate estimates for their own economic sector and for the economy as a whole.

\section{Sample characteristics}

This study is based on a simple random sample. The sample is representative of the whole Bulgarian economy. It is not representative at regional level and it is not stratified by company size, although size is observed and recorded for the study. For all statistical purposes, this is a representative sample and the results should be generalisable for the country as a whole.

Overall, 345 companies were included in the sample. Of them, 50 per cent were located in the capital city of Sofia, 34.4 per cent in regional major cities, 12.9 per cent in other cities or towns and 2.6 per cent in villages. The companies in Sofia were oversampled because more than 50 per cent of foreign investments in Bulgaria are located in the capital city. The distribution by sectors is presented in Table 1 . 
Table 1 - Distribution by economic sector

\begin{tabular}{|l|c|c|}
\hline Sector & Number & Per cent \\
\hline Agriculture & 9 & 2.6 \\
\hline Manufacturing & 55 & 16.1 \\
\hline Construction & 34 & 9.9 \\
\hline Transport & 15 & 4.4 \\
\hline Wholesale & 37 & 10.8 \\
\hline Retail trade & 44 & 12.9 \\
\hline Tourism, hotels, restaurants & 24 & 7.0 \\
\hline Communications & 13 & 3.8 \\
\hline Infrastructure & 9 & 2.6 \\
\hline Other business services & 46 & 13.5 \\
\hline Education & 10 & 2.9 \\
\hline Health care & 12 & 3.5 \\
\hline Other & 34 & 9.9 \\
\hline & & 100.0 \\
\hline Total & 342 & \\
\hline
\end{tabular}

Apart from being fairly representative, the sample was very diverse. The companies included in the survey were from 13 major economic sectors, with frequencies varying from 9 to 55 companies for each sector. It is reassuring to have an adequate number of representative firms for each of the included sectors.

The distribution by number of employees is presented in Table 2.

Table 2 - Distribution by number of employees

\begin{tabular}{|l|c|c|}
\hline Employees & Number & Per cent \\
\hline One & 18 & 5.3 \\
\hline $2-9$ & 106 & 31.4 \\
\hline $10-49$ & 96 & 28.4 \\
\hline $50-249$ & 65 & 19.2 \\
\hline 250 or more & 53 & 15.7 \\
\hline & & 100.0 \\
\hline Total & 338 & \\
\hline
\end{tabular}


The sample is very diverse with regard to company size. Over 36 per cent of the sample are very small companies, with up to 9 employees. Large companies with 250 employees or more made up almost 16 per cent of the sample. The distribution of companies by size is quite close to the size structure of enterprises in the Bulgarian economy.

The interviewees included majority owners (23.7 per cent), experts (25.4 per cent), co-owners ( 8.9 per cent), managers (18.3 per cent), CEOs ( 9.8 per cent), board members (2.1 per cent) and others (11.8 per cent). This favourable background with regard to survey respondents is an important factor in assessing the value of their answers and estimates. These are people with an in-depth knowledge of the companies' accounting practices, finance, business and marketing plans. In general, they are people familiar with balance sheets, tax filing and day-to-day business operations, as well as the strategic plans of their companies. Most of them are in executive positions and the information they provided can be expected to be based on actual facts and understanding, not on uneducated guesses.

Over a quarter of the companies (26.7 per cent) reported having partial foreign ownership or foreign investment. The presence of companies with foreign investment is very valuable for this survey. There is a widespread belief among economists that companies with foreign ownership will behave more responsibly and will resist some prevalent practices and illegal activities. We shall test this hypothesis with our data.

The majority ( 58 per cent) of the sample reported that they expected growth in the next six months; 37.5 per cent reported that they expected business activities to continue at current levels; and only 4.5 per cent expected a decrease in their activity. In general, the companies at the end of 2007 and the beginning of 2008 were optimistic about their short-term economic situation.

The credit behaviour of the companies was quite diverse: 43.1 per cent reported no outstanding credit, 31.3 per cent reported bank credits and the rest (25.6 per cent) obtained credit from other sources. These results are typical of the Bulgarian economy in general. A significant proportion of companies in Bulgaria, especially small ones, are very reluctant to take out any credit and a significant portion seek credit outside the banking system.

\section{Analysis}

All differences and relationships were tested statistically. A variety of statistical methods and models were used in this analysis. For the comparison of categorical variables the Pearson chi-square test was used, and for $2 \times 2$ table analysis the Fisher exact test was employed. For difference in means tests the one-way ANOVA and t-tests were used, and for comparison of two distributions the Kolmogorov-Smirnov and Wilcoxon Sign ranks test. For building $95 \%$ Confidence Intervals (CI) for proportions the Agresti-Coull corrected CI was used (Agresti and Coull, 1998).

\section{Overall evaluation of the hidden economy}

The respondents were asked to evaluate the size of the hidden economy as a percentage of GDP, with the following possible answers: None; up to $10 \%$; more than $10 \%$ and 
up to $25 \%$; more than $25 \%$ and up to $50 \%$; more than $50 \%$ and up to $75 \%$; more than $75 \%$. The results are presented in Table 3 .

Table 3 - Size of the hidden economy in Bulgaria

\begin{tabular}{|l|c|c|}
\hline Size (\% of GDP) & Number & Per cent \\
\hline No hidden economy & 1 & 0.3 \\
\hline Up to $10 \%$ & 4 & 1.2 \\
\hline More than $10 \%$ and up to $25 \%$ & 69 & 20.1 \\
\hline More than $25 \%$ and up to $50 \%$ & 178 & 51.9 \\
\hline More than $50 \%$ and up to $75 \%$ & 74 & 21.5 \\
\hline More than $75 \%$ & 343 & 5.0 \\
\hline Total & & 100.0 \\
\hline
\end{tabular}

More than half of the participants (52.4 per cent) evaluate the hidden economy as 25-50 per cent of GDP. Using the median of the intervals and frequencies we calculated the weighted average of the size. The size of the hidden economy in Bulgaria is estimated by the business sector to be 42 per cent of GDP. This estimate is higher than previously evaluated (author's personal correspondence with SNA, NSI). It is important to keep in mind that the 'informal' economy is not included in this estimate.

There was no statistically significant relationship between the evaluation of the hidden economy and the size of the company and the presence or absence of foreign investment in the company.

A significant portion of the sample (41.0 per cent) thought that the hidden economy had decreased in the last five years, while 32.2 per cent thought otherwise and 26.8 per cent conceded no change in the last five years. Company size and the presence of foreign investment did not have any statistical impact on this question.

Evaluation of the hidden economy in the respondent's own economic sector

The respondents were asked to evaluate the size of the hidden economy in their own economic sector and the results are presented in Table 4. 
Table 4 - Size of the hidden economy in respondent's own economic sector

\begin{tabular}{|l|c|c|}
\hline Size (\% of total production) & Number & Per cent \\
\hline No hidden economy & 30 & 8.8 \\
\hline Up to $10 \%$ & 69 & 20.2 \\
\hline More than $10 \%$ and up to $25 \%$ & 105 & 30.8 \\
\hline More than $25 \%$ and up to $50 \%$ & 92 & 27.0 \\
\hline More than $50 \%$ and up to $75 \%$ & 38 & 11.1 \\
\hline More than $75 \%$ & 7 & 2.1 \\
\hline Total & 341 & 100.0 \\
\hline
\end{tabular}

The weighted average of the size of the hidden economy in their own economic sector is 26 per cent, which is significantly lower than their estimate of the hidden economy in the country as a whole. Respondents thought that the size of the hidden economy in their own sector was much lower than in the whole economy. The size of the company had a statistically significant $(\mathrm{p}=.005)$ impact on this evaluation, as larger companies saw the hidden economy in their sector as much lower than at national level, while the smaller companies thought otherwise.

Companies with foreign investment gave lower estimates of the hidden economy compared to companies with no foreign investment $(\mathrm{p}=.046)$.

Almost half of the sample (45.8 per cent) perceived that the hidden economy in their own sector had decreased in the last five years, while 22.3 per cent thought that it had increased and 31.8 per cent did not see any change in the last five years. Company size and the presence of foreign investment did not have any statistical impact on this question.

\section{Activities associated with the hidden economy}

The respondents were asked to identify the most common activities they associate with the hidden economy. The results are presented in Table 5.

\section{Table 5 - Activities associated with the hidden economy}

\begin{tabular}{|l|c|c|}
\hline Activity & Number & Per cent \\
\hline Hiring with a contract with 'hidden' clauses & 213 & 61.7 \\
\hline Hiring without a contract & 202 & 58.6 \\
\hline $\begin{array}{l}\text { Not issuing proper sales documentation (e.g. from cash } \\
\text { registers) }\end{array}$ & 195 & 56.5 \\
\hline Not paying sales tax and other taxes, fees, etc. & 186 & 53.9 \\
\hline Pocketing VAT & 173 & 50.1 \\
\hline
\end{tabular}




\begin{tabular}{|l|c|c|}
\hline Activity & Number & Per cent \\
\hline Reporting lower profits & 166 & 48.1 \\
\hline Illegal import and export & 138 & 40.0 \\
\hline Reporting lower daily sales for accounting & 136 & 39.4 \\
\hline Receiving or giving bribes, presents, free services, etc. & 117 & 33.9 \\
\hline No open competition for large orders or auctions & 103 & 29.9 \\
\hline Large cash transactions & 46 & 13.3 \\
\hline Barter transactions & 7 & 2.0 \\
\hline Other & 4 & 1.2 \\
\hline
\end{tabular}

The two types of activity most associated with the hidden economy are hiring employees without a contract or hiring them with a contract with hidden clauses. These hidden clauses are usually related to social security payments, hiring officially at the minimum wage or lower than the actual wage, additional payments 'under the table' and so on. In the same range of prevalence are practices such as sales without sales receipts, not paying sales tax and pocketing value added tax.

Economic sectors were evaluated by the respondents with regard to the size of the hidden economy in them. The results are presented in Table 6.

Table 6 - Sectors with the largest hidden economy

\begin{tabular}{|l|c|c|}
\hline Sector & Number & Per cent \\
\hline Construction & 223 & 65.2 \\
\hline Wholesale & 149 & 43.6 \\
\hline Retail trade & 123 & 36.0 \\
\hline Restaurants & 120 & 35.1 \\
\hline Tourism & 107 & 31.3 \\
\hline Infrastructure & 82 & 24.0 \\
\hline Health care & 65 & 19.0 \\
\hline Agriculture & 63 & 18.4 \\
\hline Education & 30 & 8.8 \\
\hline Transport & 27 & 7.9 \\
\hline Manufacturing & 23 & 6.7 \\
\hline Communications & 8 & 2.3 \\
\hline Other & 5 & 1.5 \\
\hline
\end{tabular}


The three sectors with the largest hidden economies were construction, wholesale and retail. These results reaffirm the belief of many economists that there are large differences and different possibilities for the presence of a hidden economy in different macroeconomic sectors. From the survey, it seems that the sectors more resistant to the influence of the hidden economy are: communications, manufacturing, transportation and education.

The respondents were asked to consider the reasons for the existence of a hidden economy in Bulgaria. The distribution of their answers is presented in Table 7.

Table 7 - Reasons for the existence of the hidden economy

\begin{tabular}{|l|c|c|}
\hline Reason & Number & Per cent \\
\hline Corruption & 201 & 58.9 \\
\hline No penalty for some illegal activities & 142 & 41.6 \\
\hline Ineffective judicial system & 101 & 29.6 \\
\hline High level of taxes & 100 & 29.3 \\
\hline The existence of organised crime & 100 & 29.3 \\
\hline Desire to get rich quick & 93 & 27.3 \\
\hline Ineffective laws & 86 & 25.2 \\
\hline Ineffective tax collection and supervision & 83 & 24.3 \\
\hline Complicated and slow administration & 67 & 19.6 \\
\hline Cultural characteristics of Bulgarian enterprise & 45 & 13.2 \\
\hline Weak border and customs controls & 23 & 6.7 \\
\hline Other & 4 & 1.2 \\
\hline
\end{tabular}

The results confirmed the theoretical expectation that the presence of corruption is the principal reason for the existence of a hidden economy in Bulgaria. The next two reasons by order of importance are the lack of penalties for some illegal activities and the ineffective judicial system. These two reasons are closely related to the presence of corruption and organised crime in Bulgaria. The high tax burden takes fourth place as a reason for the existence of a hidden economy, with just under 30 per cent of respondents listing this reason. The remaining reasons in the list are expected and confirm theoretical expectations, but are not dominant.

The negative consequences of the hidden economy were an important part of the survey. The results are presented in Table 8. 
Table 8 - Negative consequences of the hidden economy

\begin{tabular}{|l|c|c|}
\hline Consequences & Number & Per cent \\
\hline Unfair competition & 222 & 66.1 \\
\hline Individual companies monopolise some sectors & 131 & 39.1 \\
\hline Loss of clients, sales decline & 112 & 33.3 \\
\hline Lower profit due to additional expenses & 102 & 30.4 \\
\hline Difficult to hire high quality employees & 87 & 25.9 \\
\hline Cheap import of comparable goods & 68 & 20.2 \\
\hline Personnel problems, lower employment & 47 & 14.0 \\
\hline Difficulty finding new investments & 44 & 13.1 \\
\hline Increased risk of default and bankruptcy & 43 & 12.8 \\
\hline Other & 9 & 2.7 \\
\hline
\end{tabular}

The main effect of the hidden economy in Bulgaria is considered to be unfair competition - two-thirds of the respondents agreed with this conclusion. The second outcome is the formation of monopolies and the dominance of single companies in some economic sectors. Also listed as troubling consequences are the loss of sales and clients, lower profits and so on. Unfair competition and monopolies, paired with the abovementioned ineffective judicial system, represent a deadly combination for companies in Bulgaria. The strengthening of the judicial system and the enforcement of business laws would ameliorate the adverse effects of the hidden economy significantly.

The respondents in the survey were asked what measures might be taken to limit the hidden economy. The results are presented in Table 9.

\section{Table 9 - Measures for limiting the hidden economy}

\begin{tabular}{|l|c|c|}
\hline Measures & Number & Per cent \\
\hline Reduce corruption & 220 & 65.1 \\
\hline Increase the effectiveness of the judicial system & 161 & 47.6 \\
\hline Introduce more effective stimuli for business & 149 & 44.1 \\
\hline Increase tax supervision & 145 & 42.9 \\
\hline Strengthen the laws & 135 & 39.9 \\
\hline Reduce VAT & 122 & 36.1 \\
\hline Improve the quality of administrative procedures & 112 & 33.1 \\
\hline Limit the influence of organised crime & 102 & 30.2 \\
\hline Reduce social security payments & 89 & 26.3 \\
\hline
\end{tabular}




\begin{tabular}{|l|c|c|}
\hline Measures & Number & Per cent \\
\hline Reduce profit tax & 81 & 24.0 \\
\hline Reduce personal income tax & 56 & 16.6 \\
\hline Make credits more available & 49 & 14.5 \\
\hline Increase border controls & 40 & 11.8 \\
\hline Reduce excise duty & 36 & 10.7 \\
\hline Other & 6 & 1.8 \\
\hline
\end{tabular}

Again, not surprisingly, fighting corruption is the principal measure proposed to limit the hidden economy. This is a very important result because it shows that economic reasons and measures are not the most potent instrument for curtailing the hidden economy. Fighting corruption is also mainly a fight against the hidden economy. Corruption and the hidden economy are not separate issues, but closely interconnected.

The survey included questions about the respondents' evaluation of the different elements of the hidden economy.

\section{Hiring without a contract}

Two-thirds (65.1 per cent) of the respondents acknowledge using this practice. The $95 \%$ Agresti-Coull CI is $(59.8 \%-70.0 \%)$. The practice is more widespread in small and medium-sized companies than in larger companies $(\mathrm{p}=.016)$. Companies with foreign investment tend to limit this practice in comparison to exclusively Bulgarianowned companies $(\mathrm{p}<.001)$.

Overall, on average, 10.1 per cent of employees are hired without a contract, the highest proportions being in construction ( 23.5 per cent) and agriculture ( 22.8 per cent) and the lowest in education (2.5 per cent) and health care (3.1 per cent).

\section{Hiring on the basis of contracts with hidden clauses}

The overwhelming majority of companies ( 82.3 per cent) acknowledge that this practice exists, to a greater or lesser extent. The $95 \%$ Agresti-Coull CI is $(77.8 \%-86.0 \%)$. The practice is more widespread in small and medium-sized companies than in larger companies $(\mathrm{p}=.009)$. As in the case of hiring without a contract, companies with foreign investment tend to limit this practice compared to solely Bulgarian-owned companies, in which it is more prevalent $(\mathrm{p}<.001)$.

Overall, on average, 31.8 per cent of employees are hired on a contract with hidden clauses, the highest proportions being in communications (43.7 per cent), construction (37.4 per cent), the retail trade (35.1 per cent) and other $(35.3 \%)$. The lowest rates for this practice are in education (10.3 per cent), health care (16.5 per cent) and infrastructure (16.4 per cent). 


\section{Reporting lower profits}

The majority ( 83.8 per cent) of respondents acknowledged the existence of this practice. The $95 \%$ Agresti-Coull CI is $(79.5 \%-87.3 \%)$. It is more widespread in small and medium-sized companies than in larger companies $(\mathrm{p}=.017)$. Companies with foreign investment tend to use this practice less than companies with no foreign investment $(\mathrm{p}=.001)$.

\section{Avoiding taxes and customs and excise duties}

Two-thirds of respondents (70.5 per cent) acknowledged avoiding taxes and customs and excise duties. The $95 \%$ Agresti-Coull CI is $(65.5 \%-75.1 \%)$. Companies with foreign investment are less likely to resort to this practice in comparison to companies without foreign investment $(\mathrm{p}=.01)$. There is no statistically significant difference between small and medium-sized companies and large companies $(p=.263)$ with regard to this practice. Nevertheless, the size of the effect is in the expected direction (43.1 per cent of large companies deny using this practice in comparison to 27.3 per cent of small and medium-sized companies).

Not giving proper sales receipts (for example, invoices, receipts from cash registers and so on)

Most respondents (70.4 per cent) admitted using this practice. The $95 \%$ Agresti-Coull $\mathrm{CI}$ is $(65.4 \%-75.0 \%)$. Larger companies use this practice less frequently $(\mathrm{p}=.004)$, as do companies with foreign investment $(\mathrm{p}<.001)$.

Reporting lower daily sales for official accounting purposes

The majority ( 81.6 per cent) of respondents admitted using this practice. The $95 \%$ Agresti-Coull CI is $(77.0 \%-85.4 \%)$. Firms with foreign investment use this practice more sparingly than those without it $(\mathrm{p}=.007)$ and larger firms use it less than smaller companies $(\mathrm{p}=.028)$.

\section{Large cash transactions}

Two-thirds (68.8 per cent) of the companies utilise large transactions in cash. The $95 \%$ Agresti-Coull CI is (63.6\%-73.6\%). This practice is used less in large companies, although the difference with smaller companies is not statistically significant (but it is in the expected direction). Companies with foreign investment tend to use it less but the difference with other companies is not statistically significant $(\mathrm{p}=.072)$.

\section{Paying lower taxes by using 'creative' accounting}

Almost all companies (95.6 per cent) report the use of creative accounting to reduce taxes in their own sector. The $95 \%$ Agresti-Coull CI is $(92.8 \%-97.4 \%)$. Obviously, this practice is the rule rather than the exception and, in combination with a number of other factors, its existence is only to be expected. The tax collection process is very inefficient and audits are very rare. 
Relationship between estimates for the respondent's own sector and the overall economy

Respondents evaluated the hidden economy in Bulgaria as constituting 42 per cent of GDP, while their estimate for the hidden economy in their own sector was much lower, at 26 per cent of total production. This difference is statistically significant $(\mathrm{p}<.001)$.

The results are presented in Table 10.

\section{Table 10 - Estimates of hidden economy by sector (\%)}

\begin{tabular}{|l|c|c|}
\hline Sector & Own sector & Whole country \\
\hline Agriculture & 35.8 & 36.4 \\
\hline Manufacturing & 24.5 & 42.0 \\
\hline Construction & 42.4 & 43.6 \\
\hline Transport & 23.8 & 41.3 \\
\hline Wholesale & 25.9 & 42.3 \\
\hline Retail trade & 27.8 & 41.8 \\
\hline Tourism, hotels, restaurants & 29.5 & 38.0 \\
\hline Communications & 19.6 & 43.7 \\
\hline Infrastructure & 18.1 & 40.8 \\
\hline Other business services & 14.9 & 40.4 \\
\hline Education & 20.8 & 47.3 \\
\hline Health care & 17.7 & 43.3 \\
\hline Other & 29.7 & 45.7 \\
\hline & & 42.1 \\
\hline Overall (Average) & 26.0 & \\
\hline
\end{tabular}

This is a very fruitful comparison. First, there are some sectors in which the sectoral and the overall hidden economy sizes are evaluated as almost the same - for example, agriculture and construction. Second, the majority of respondents evaluated the size of the hidden economy in their own sector as much lower than its size in the economy as a whole - for example, manufacturing, wholesale, transportation and so on. This difference is probably due to psychological bias, but the available information and data were not sufficient to definitively understand and test this difference.

\section{Discussion}

This study represents the results of independent research into the hidden economy in Bulgaria. Some of the existing estimates in the literature are outdated and this study supplies recent data on this important issue. It is particularly valuable because it covers 
the period since Bulgaria joined the EU. In addition, this study covers more ground by specifically investigating the reasons for the existence of the hidden economy, its main consequences, sectoral distribution and so on. Major economic factors such as company size and the presence of foreign investment were also considered.

The study has a number of limitations. The main limitation is that it does not include an evaluation of the 'informal' economy, which is an integral part of the hidden economy. On the other hand, there are some reliable estimates of the 'informal' economy, such as the one by the Bulgarian NSI. If desired, our estimates can be augmented with the segment of the 'informal' economy computed by NSI.

The main value of this research is related to its timing and its sources. The respondents were in a position to evaluate the size of the unreported or underreported part of their company production and to estimate the size of the hidden economy in their own sector. They have contacts with other sectors of the economy so can make an educated guess about the hidden economy in the whole economy.

The larger size of the hidden economy observed by this study is not a complete surprise. At different times, particularly before Bulgaria joined the EU, other researchers have come to similar conclusions (for example, Schneider, 2006). What is disturbing is that, even after EU accession, the hidden economy in Bulgaria is still 42 per cent of GDP, which, compared to other east European countries, is relatively high and has not diminished significantly in the last five years.

The Bulgarian business community's evaluations have confirmed some theoretically important constructs, particularly about the close relationship between the hidden economy and corruption. The latter is considered both the main cause and the main consequence of the existence of the hidden economy. The fight to reduce corruption is at the same time a fight to reduce the size of the hidden economy.

Another confirmation of theoretical value is the fact that companies with foreign investment are less susceptible to the illegal activities and doubtful business practices that are major sources of and fuel for the hidden economy. Also, larger companies tend to behave better than smaller companies when it comes to complying with the law.

The sectoral distribution of the hidden economy confirmed many economists' belief that some sectors are more prone to the existence of a hidden economy than others. This finding has obvious implications for the design of policies to curb this negative phenomenon. More specific and differentiated guidelines have to be implemented in accordance with sectoral differences in this area.

Some of the empirical findings, although expected, are nonetheless extremely disturbing: for example, the estimates that 83 per cent of companies in Bulgaria hire employees on contracts with hidden clauses and 66 per cent hire employees without a labour contract. This practice also has obvious implications for tax revenue and social security payments. More than two-thirds of companies use other irregular practices, such as reporting lower profits, tax avoidance, not issuing proper sales receipts and so on.

It is obvious that the problem of the hidden economy in Bulgaria nowadays is persistent and, in turn, generates further corruption and other improper practices. To fight the hidden economy we must, first, fight corruption, dramatically improving the efficiency of the judicial system and diligently applying the law. Studies like this one, 
probably in reduced form, should be conducted more frequently - preferably annually

- thereby providing policy-makers, researchers and the public with more up-to-date and timely information on the hidden economy.

\section{References}

Agresti, A. and B. Coull (1998) 'Approximate is better than 'exact' for interval estimation of binomial proportions' The American Statistician 52: 119-26.

Belev, B (2002) The informal economy in the EU accession countries World Bank and Centre for Study of Democracy (CSD).

Belev, B (2003) The informal economy in the EU accession countries: size, scope, trends and challenges in the process of EU enlargement Sofia: Centre for Study of Democracy, available at: www.csd.bg (in Bulgarian).

CSD (2003) The informal economy in the EU accession countries: size, scope, trends and challenges in the process of EU enlargement Sofia: Centre for Study of Democracy, available at: http://www.csd.bg (in Bulgarian).

CSD (2004) Hidden economy in Bulgaria Sofia: Centre for Study of Democracy (in Bulgarian).

Dudeva, L (2001) Statistical aspects of the unobserved economy Sofia: Centre for Economic Development (in Bulgarian).

Feige, E. and I. Urban (2007) Measuring underground (unobserved, non-observed, unrecorded) economies in transition countries: can we trust GDP? MPRA, University of Munich.

Goev, V (2007) 'Some issues concerning approaches to the statistical study of the hidden economy' in: Current issues of statistical theory and practice in Bulgaria Sofia: UNWE Press (in Bulgarian).

Goev, V. and V. Boshnakov (2008) 'Grey economy and perspectives of Bulgarian business development during the EU accession period' Ekonomika Journal 84: 2939 (School of Economics, University of Vilnius, Lithuania).

Goev, V. and V. Boshnakov (2003) 'Estimates of hidden economy size in Bulgaria' in P. Iliev (Ed.) Informal economy in EU candidate countries Sofia: CSD (in Bulgarian).

Iliev, P (Ed.) (2004) The hidden economy in Bulgaria Sofia: CSD (in Bulgarian).

Kyle, S, A. Warner, K. Stanchev, S. Alexandrova, L. Dimitrov and R. Krustev (2001) Measuring the shadow economy in Bulgaria Sofia: IME, AEAF, Harvard University and Cornell University.

OECD (2002a) Measuring the Non-Observed Economy: A Handbook Paris: OECD.

OECD (2002b) Handbook of NOE (Annex 4: Analytical Framework for the Non-observed Economy), Paris: OECD.

Schneider, F (2006) Shadow economies around the world: what do we know? Institute for Labor Studies IZA DP, No. 1043. 
Schneider, F. and D. Enste (2002) The shadow economy: an international survey Cambridge: Cambridge University Press.

Schneider, F. and R. Klinglmair (2004) Shadow economies around the world: what do we know? Institute for Labor Studies IZA DP, No. 1043.

Stoikov, I. and P. Dimitrova (1999a) Hidden economy - measurement and influence, Ikonomicheski Izsledvania 1: 3-43 (in Bulgarian).

Stoikov, I. and P. Dimitrova (1999b) Hidden economy in Bulgaria Ikonomicheski Izsledvania 1: 44-75 (in Bulgarian). 